\title{
Estimation of Storm-centered ARF Using Radar Rainfall by Duration and Return Periods
}

\author{
Eunji Kim and Boosik Kang* \\ Department of Civil and Environmental Engineering, Dankook University, Korea \\ ${ }^{*}$ Corresponding author
}

\begin{abstract}
Design flood estimation, the application of the Areal Reduction Factor (ARF) is essential to convert the point rainfall to areal rainfall for the reference area. ARF calculation methods are largely divided into fixed-area method and storm-centered method. Since ARF is calculated by independent frequency analysis of maximum annual areal rainfall and point rainfall. On the other hand, storm-centered method is that make the maximum rainfall occur by spatial transition of each rainfall event to the center of the analysis watershed. Using the radar rainfall data, it is possible to calculate the real ARFs. In this study, the storm-centered ARFs were estimated by using radar data of the flood season (June to September) of 2007-2012 provided by Korea Meteorological Administration. Also, the center rainfall of the radar data were classified by the probability rainfall based on gauge rainfall data, and storm-centered ARFs were compared with fixed-area ARFs by duration and return period.
\end{abstract}

Keywords-Areal Reduction Factor(ARF); radar rainfall; stormcentered method

\section{INTRODUCTION}

The design flood is that used to determine the size of hydraulic structures. In order to estimate the design flood, the probability rainfall estimated according to the duration and return period of the rainfall is used in Korea. At this time, it is essential to estimate the areal rainfall for targeted watershed.

Since the point rainfall is a value representing limited area only, Areal Reduction Factor (ARF) is applied to convert the point probability rainfall into the areal rainfall with the reference area. Methods of estimating ARF are mainly based on empirical methods, which are based on observational data of past period, and empirical methods are classified into fixedarea method and storm-centered method. Fixed-area method estimates ARFs by dividing the average area rainfall of the annual maximum rainfall for a specific area and duration by the point rainfall for the same area and duration [1-2]. Also, ARFs were estimated by averaging the ratio of area rainfall to annual maximum point at each station [3]. ARFs were calculated by analyzing the frequency of point rainfall and Thiessen weighted averaging rainfall for a specific return period [4], and ARFs for the sub-watershed was estimated by Thiessen weighted averaging areal rainfall of the entire watershed divided by the maximum point rainfall at each station [5]. In South Korea, it is recommended to apply fixed-area method to estimation of areal probability rainfall by exponential fitting regression constants of ARFs curve for some regions [6]. However, since fixed-area method is estimated by the independent frequency analysis of annual maximum areal rainfall and point rainfall, it cannot be regarded as synchronized rainfall.

On the other hand, storm-centered method is interpreted the center of rainfall in the center of the area for individual synchronized rainfall events. Since storm-centered ARFs estimate the areal rainfall by reflecting the spatial distribution characteristics of rainfall, recent studies have been carried out to estimate ARFs using radar data. Radar rainfall data can identify the spatial structure of the rainfall and serve as a key factor in inducing ARFs [7]. In general, storm-centered ARFs using radar rainfall are lower than fixed-area ARFs, and they also varies with reference area, duration, and return periods [810] calculated the storm-centered ARFs reflecting the regional and rainfall characteristics of the Texas region by selecting the optimal elliptical shape according to the shape of the rainfall.

Fixed-area ARFs are estimated based on the assumption that the probability rainfall occurs at all points in the reference area at the same time, which imply that the possibility of being overestimated from ARFs of actual rainfall. While stormcentered ARFs using radar data may effectively reflect the spatial distribution characteristic of rainfall events occurring in the same time. Therefore, in this study, the method of estimating the areal rainfall by searching the optimal area of the circle and ellipse considering the shape of rainfall events [10] was applied to estimate storm-centered ARF of the Han-river basin. Then storm-centered ARFs were estimated by duration and return period, and compared with the previously reported fixed-area ARFs.

\section{STUDY AREA AND MATERIALS}

\section{A. Radar Rainfall Data}

The weather radar is a remote sensing observation device that emits radio waves into the atmosphere and collides with the precipitation particles. It can detect the rainfall area, rainfall intensity, and moving rate by using a signal scattered back. In addition, it provides high resolution radar rainfall so it detects the rainfall phenomena such as heavy rain, typhoon and hail in a short time in three dimensions.

Currently, Korea Meteorological Administration (KMA) has installed and operate weather radars at 10 locations nationwide. The image data observed by each weather radar devices is synthesized every 10 minutes and is provided as a nationwide composite radar image. 


\section{B. Study Area}

Han-river basin, which is selected as study area, is located in the central part of the Korean peninsula. It has a watershed area of $34,428 \mathrm{~km}^{2}$, an extension of $483 \mathrm{~km}$, an average width of $69.8 \mathrm{~km}$, and is Korea's largest river basin with a watershed shape factor of 1.49(Figure 1). It is characterized by the eastern part of the mountain, which is distributed mainly in the mountains between $500 \sim 1,500 \mathrm{~m}$ above sea level. Also, meteorologically, it is characterized by the occurrence of $65 \%$ of the total rainfall in the flood season due to heavy rains caused by typhoons and heavy rainfall between June and September.

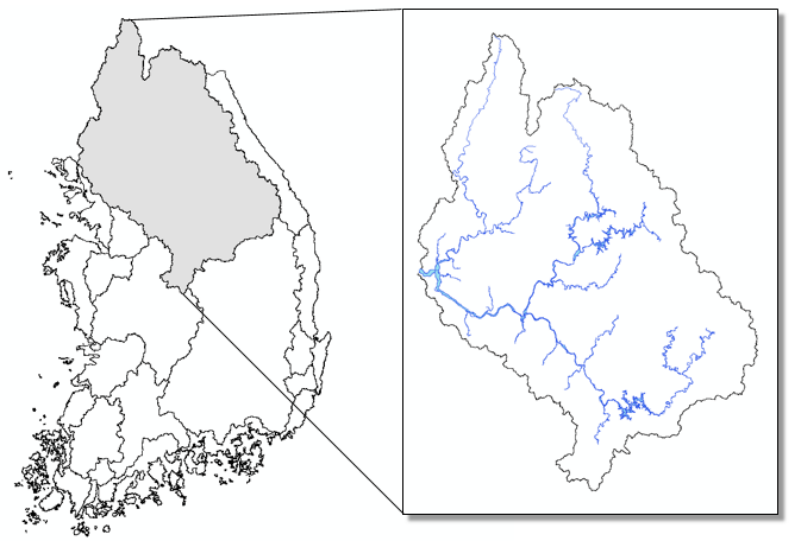

FIGURE I. HAN-RIVER BASIN IN THE KOREAN PENINSULA

\section{METHOdOLOGY}

\section{A. Processing of Radar Data}

The signal that is emitted from the weather radar and reflected on the precipitation particle is called reflectivity coefficient $(Z)$ and expressed in decibels. dBZ is the radar reflectivity unit based on the droplet of $1 \mathrm{~mm}$ diameter per unit volume as follows.

$$
\mathrm{dBZ}=10 \log Z
$$

The received radar reflection intensity is related to the number of raindrops and diameter that exist within unit volume. Also, rainfall intensity is related to the number of raindrops and diameter in unit volume as well as rate of dropping rainfall. Thus, reflectivity coefficient $(Z)$ and rainfall intensity (R) have a correlation with each other, and Z-R relationship is proposed by establishing this correlation. Z-R relationship that is empirical and statistical relationship between radar reflectivity coefficient and rainfall intensity is shown in the following equation.

$$
\mathrm{Z}\left(\mathrm{mm}^{6} / \mathrm{m}^{3}\right)=\alpha R^{\beta}
$$

Where $\mathrm{R}$ is rainfall intensity, $\alpha$ and $\beta$ are empirical constant and various $\alpha$ and $\beta$ were proposed depending on type of rainfall. In this study, $\alpha$ and $\beta$ proposed by Marshall and
Palmer (1948) for middle-latitude layered rainfall, which is most widely used, were applied.

$$
\mathrm{Z}=200 R^{1.6}
$$

Radar intensity(R) was calculated from the reflectivity factor $(Z)$ measured by the weather radar and radar intensity $(\mathrm{mm} / \mathrm{hr})$ was converted to precipitation $(\mathrm{mm})$.

\section{B. Estimating Storm-centered ARF Using Radar Data}

Storm-centered ARF based on radar rainfall data is estimated by dividing the areal rainfall of specific rainfall event by point rainfall at the center of the areal rainfall and the process is shown in Figure 2.

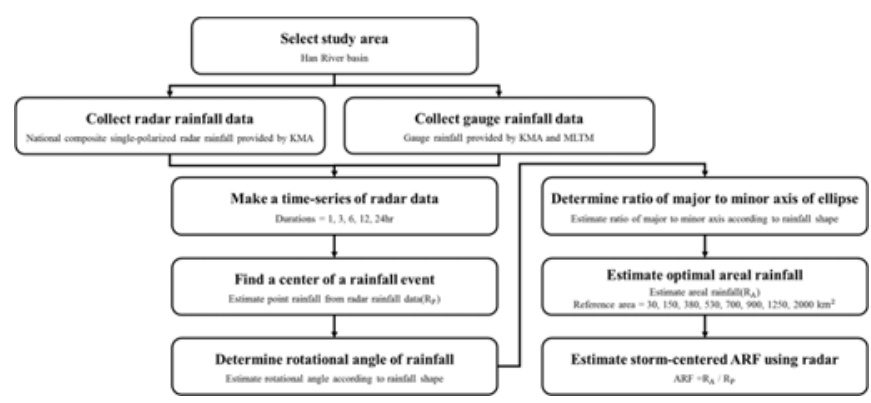

FIGURE II. SCHEMATIC DIAGRAM FOR ESTIMATING OF STORMCENTERED ARF USING RADAR DATA

Rainfall intensity was estimated from the reflectivity coefficient measured by weather radar and rainfall intensity was converted into rainfall to produce radar rainfall data in units of 10 minutes. Radar rainfall data for each 10 minutes period were accumulated for each durations $(1,3,6,12$, 24hours).

The center of coordinates of rainfall events were selected from the annual maximum rainfall series expressed by radar rainfall images. Rainfall intensity is highest at the center of the rainfall, and decreases with distance from the center. Therefore, the coordinates of the grid where the maximum rainfall occurs in the corresponding rainfall event were selected, when the center coordinates was selected. However, considering the uncertainty of rainfall of the center coordinate as the central rainfall, it was estimated that the mean value of the center coordinate and the surrounding 8 grids was considered as the central rainfall. This value can be defined as the point rainfall estimating ARF. Since the area of rainfall is narrow and the long-banded rainfall occurs frequently in Korea, in this study, the area of rainfall was determined as the circle and ellipse considering the shape and direction of rainfall when estimating the areal rainfall.

In order to estimate the areal rainfall of the elliptical shape, skewness analysis was performed to determine the direction angle of the major axis of the ellipse corresponding to the shape of the rainfall, and the angle when the negative skewness was largest was determined as the optimal direction angle. The direction angle of major axis was increased from $0^{\circ}$ to $175^{\circ}$ in $5^{\circ}$ increments. When the direction angle was determined, the ratio of major to minor axis of the ellipse was changed form 
1:1(circle) to $15: 1$ (ellipse) to estimate maximum areal rainfall and it was increased by 0.5 from $1: 1$ to $4: 1$ and 1 from $4: 1$ to $15: 1$. The areal rainfall at the reference area of $1,250 \mathrm{~km}^{2}$ was compared and the areal rainfall at the ratio of major to minor axis corresponding to the maximum value was determined as the optimal areal rainfall [11]. Areal rainfall corresponding to the reference area of $30,150,380,530,700,900,1250$ and $2000 \mathrm{~km}^{2}$ were estimated from the point rainfall using the optimal ratio of major to minor axis.

In this way, the point rainfall of each rainfall events and the optimal areal rainfall by each reference areas can be estimated. Storm-centered ARF is estimated by the following formula using the ratio of the point rainfall to the areal rainfall (Eq. (4)).

$$
A R F_{A}=\frac{A \int R_{P} d A}{R_{P 0}}
$$

Where $\mathrm{A}\left(\mathrm{km}^{2}\right)$ is the area of a circle or ellipse determined from the shape of rainfall, $A R F_{A}$ is the $\mathrm{ARF}$ of area $\mathrm{A}, R_{P}$ is the radar rainfall $(\mathrm{mm})$ of each grid located in a circle of ellipse, and $R_{P 0}$ is the point rainfall $(\mathrm{mm})$ of center of rainfall.

\section{Deriving ARF Curve}

The equation for ARF curve (areal reduction curve) was derived by exponential fitting equation presented by [12] for storm-centered ARF by return period and duration and the exponential fitting equation is as follow as Eq. (5).

$$
\operatorname{ARF}(\mathrm{A})=1-M \exp \left[-\left(a A^{b}\right)^{-1}\right]
$$

Where $\mathrm{M}, \mathrm{a}$ and $\mathrm{b}$ are parameter and $\mathrm{A}$ is area $\left(\mathrm{km}^{2}\right)$ and the equation that constant term was transposed to left side is as follow as Eq. (6).

$$
1-\operatorname{ARF}(\mathrm{A})=M \exp \left[-\left(a A^{b}\right)^{-1}\right]
$$

Log is applied to both sides and summarized as follows as Eq. (7) (9).

$$
\begin{gathered}
\log [1-\operatorname{ARF}(\mathrm{A})]=\log M-\left(a A^{b}\right)^{-1} \\
-\log \left[\frac{1-\operatorname{ARF}(\mathrm{A})}{M}\right]=\frac{1}{a A^{b}} \\
-\log \left[\frac{1-\operatorname{ARF}(\mathrm{A})}{M}\right]^{-1}=a A^{b}
\end{gathered}
$$

Log is once again applied to both sides and summarized as follow as Eq. (10).

$$
\log \left[-\log \left[\frac{1-\mathrm{ARF}(\mathrm{A})}{M}\right]^{-1}\right]=\log a+b \log A
$$

In this case, the standard equation of the linear regression form can be derived by using $\mathrm{Y}$ as left sides, $\log \mathrm{a}$ as $\mathrm{C}, \mathrm{b}$ as $\mathrm{D}$, and $\log \mathrm{A}$ as $\mathrm{X}$, and parameters of exponential fitting equation were estimated (Eq. (11)).

$$
\mathrm{Y}=\mathrm{C}+\mathrm{DX}
$$

\section{RESUlT}

Storm-centered ARFs using radar rainfall data were calculated for duration 1, 3, 6, 12, and 24 hours and they were classified based on point rainfall from 0 to 10 years, 10 to 20years, 20 to 50 years, 50 to 80 years, and 80 to 100 years.

Fixed-area ARFs with 10, 20, 50, 80, and 100 years of return period for each duration referred to [6] are compared with storm-centered ARFs. Storm-centered ARFs are calculated for each rainfall event, so values of the reference areas $30,150,380,530,700,900,1250,2000 \mathrm{~km}^{2}$ are simple averaged. Fixed-area and storm-centered ARFs decreased with increasing reference area in accordance with the spatial distribution characteristics of rainfall events and storm-centered ARF curve showed a larger reduction compared to fixed-area. These results are the same for all durations and return periods (Figure 3), and the regression constants of the calculated stormcentered ARF curves are as shown in Table 1.

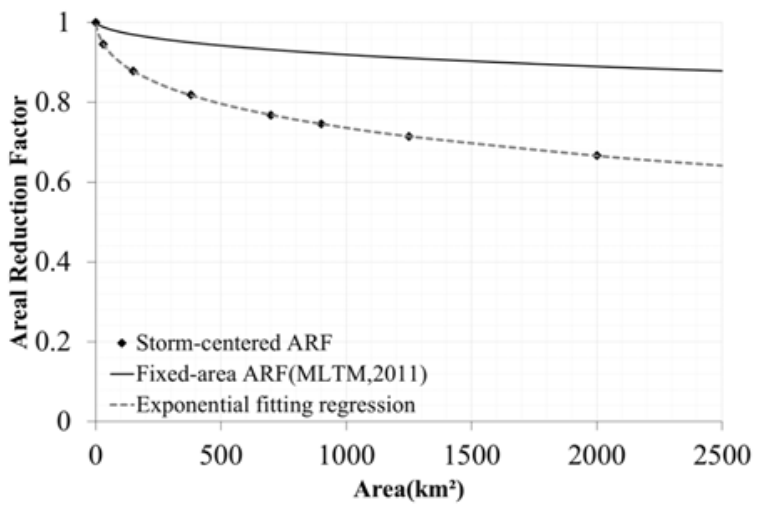

(A)

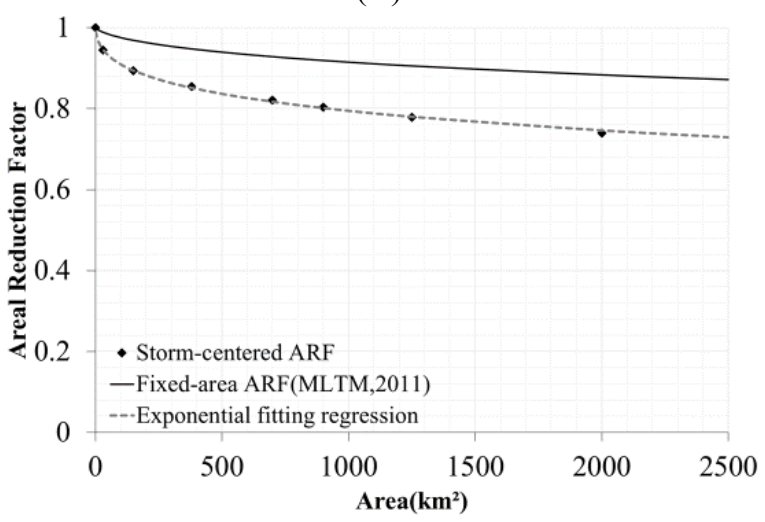

(B)

FIGURE III. ARF CURVES OF STORM-CENTERED ARF BY DURATION AND RETURN PERIOD OF HAN RIVER(A: 12 HOURS DURATION AND 50 80 YEARS RETURN PERIOD, B : 24 HOURS DURATION AND 80 100 YEARS RETURN PERIOD) 
TABLE I. REGRESSION CONSTANTS OF STORM-CENTERED ARFS USING RADAR DATA BY DURATION AND RETURN PERIOD

\begin{tabular}{|c|c|c|c|c|c|c|}
\hline \multirow{2}{*}{$\begin{array}{l}\text { Return } \\
\text { Period }\end{array}$} & \multirow{2}{*}{$\begin{array}{c}\text { Regression } \\
\text { Constant }\end{array}$} & \multicolumn{5}{|c|}{ Duration(hr) } \\
\hline & & 1 & 3 & 6 & 12 & 24 \\
\hline \multirow{3}{*}{$0 \sim 10 \mathrm{yr}$} & M & 1.360 & 1.303 & 1.069 & 1.458 & 3.870 \\
\hline & a & 0.121 & 0.120 & 0.116 & 0.171 & 0.149 \\
\hline & $\mathrm{b}$ & 0.351 & 0.307 & 0.313 & 0.198 & 0.133 \\
\hline \multirow{3}{*}{$10 \sim 20 \mathrm{yr}$} & M & 1.284 & 1.154 & 1.477 & 3.180 & 4.982 \\
\hline & $\mathrm{a}$ & 0.122 & 0.121 & 0.140 & 0.162 & 0.118 \\
\hline & $\mathrm{b}$ & 0.377 & 0.342 & 0.230 & 0.132 & 0.132 \\
\hline \multirow{3}{*}{$20 \sim 50 \mathrm{yr}$} & M & 1.316 & 1.050 & 1.290 & 2.994 & 4.998 \\
\hline & $\mathrm{a}$ & 0.147 & 0.125 & 0.150 & 0.155 & 0.158 \\
\hline & $\mathrm{b}$ & 0.354 & 0.384 & 0.253 & 0.125 & 0.099 \\
\hline \multirow{3}{*}{$50 \sim 80 \mathrm{yr}$} & M & 1.403 & 1.264 & 1.425 & 3.894 & 4.748 \\
\hline & $\mathrm{a}$ & 0.163 & 0.214 & 0.201 & 0.148 & 0.148 \\
\hline & $\mathrm{b}$ & 0.323 & 0.277 & 0.215 & 0.130 & 0.107 \\
\hline \multirow{3}{*}{$80 \sim 100 \mathrm{yr}$} & M & - & 1.411 & 1.806 & 3.572 & 5.000 \\
\hline & a & - & 0.162 & 0.123 & 0.131 & 0.110 \\
\hline & b & - & 0.294 & 0.222 & 0.147 & 0.134 \\
\hline
\end{tabular}

\section{DISCUSSION AND CONCLUSION}

Unlike fixed-area ARFs which annual maximum areal rainfall and point rainfall are independently analyzed by frequency, storm-centered ARFs are estimated as the ratio of areal rainfall to point rainfall at the same time, in addition, realistic ARF can be determined by estimating areal rainfall by selecting the optimal circle and ellipse through radar rainfall data.

Storm-centered ARFs by the duration and reference area were classified by the point rainfall based on the probability rainfall, and arithmetic average of ARFs was calculated as final storm-centered ARF of specific return period and duration.

However, since the available period of radar data is as short as 6 years, it is difficult to obtain various frequency of rainfall events. As a result of comparing the number of rainfall events by return period, the number of considered rainfall events decreased drastically as return period became longer. Therefore, it is considered that ARFs estimated from the 80-100 year return period is not representative of return period. In order to overcome these limitations, sufficient radar rainfall events should be secured at various frequencies.

As a result of comparison with ARF curve, both fixed-area and storm-centered ARFs decreased with increasing reference area in accordance with the spatial distribution characteristics of rainfall events. However, storm-centered ARFs estimated based on the actual rainfall events showed a large decrease rate relative to the reference area, and fixed-area ARFs are overestimated compared to storm-centered ARFs.

ARF curves by duration and return period presented in this study can be compared with fixed-area ARF and storm- centered ARF. However, the relationships among duration, return period, and ARF were not discussed in this study. However, the relationship among ARF, duration and return period was not discuss in this study. If the relation of ARF according to duration and return period is investigated through continuous research, it is considered that storm-centered ARFs can be actively used in the realistic and economical design of hydraulic structures.

\section{ACKNOWLEDGMENT}

This research was financially supported by a grant (11Tech-Inovation-C06) from Advanced Water Management Research Program funded by Ministry of Land, Infrastructure, and Transport of Korean government.

\section{REFERENCES}

[1] U. S. Weather Bureau. Rainfall Intensity-Frequency Regime 1. The Ohio Valley, Tech. Paper 29. U.S. Department of Commerce: Washington, D.C, USA, 1957

[2] U. S. Weather Bureau. Rainfall Intensity-Frequency Regime 2. Southeastern United States Tech. Paper 29. U.S. Department of Commerce : Washington, D.C, USA, 1958.

[3] NERC. Flood studies report, Volume II. Natural Environment Reseach Council : London, UK, 1975

[4] Bell, F. C. The areal reduction factor in rainfall frequency estimation. Institute of Hydrology Report No.35. NERC : London, UK, 1976.

[5] Desbordes, M.; Raous, P.; Trevisiol, Y. Areal reduction factors on short time and space intervals. Water Science and Technology. 1984, 16.8-9, 189-198.

[6] MLTM. Study on improvement and supplement of Probability Rainfall in South Korea. Ministry of Land, Transport and Maritime Affairs : Sejong, Korea, 2011

[7] Bacchi, B; Ranzi, R. On the derivation of the areal reduction factor of storms. Atmospheric Research. 1996, 42.1, 123-135.

[8] Durrans, S. Rocky, Lesley T. Julian, and Michael Yekta. "Estimation of depth-area relationships using radar-rainfall data." Journal of hydrologic Engineering 7.5 (2002): 356-367.

[9] Martins, J. R. S., L. S. Girnius, and M. G. M. Pinto. "Point to area rainfall relationships using radar data." São Paulo (2014)

[10] Olivera, Francisco, et al. "Estimation of average rainfall areal reduction factors in Texas using NEXRAD data." Journal of Hydrologic Engineering 13.6 (2008): 438-448.

[11] Lee, D. Estimation of storm-centered areal reduction factor using radar rainfall, Dankook University : Yongin, Korea, 2014.

[12] Lee, K. A study on the regional frequency analysis of the point rainfall : applied in the Han river basin, Yonsei University : Seoul, Korea, 1984 